\title{
Transcriptional Control of Cell Lineage Development in Epicardium-Derived Cells
}

\section{Caitlin M. Braitsch and Katherine E. Yutzey *}

The Heart Institute, Division of Molecular Cardiovascular Biology, Cincinnati Children's Hospital Medical Center, 240 Albert Sabin Way ML 7020, Cincinnati, OH 45229, USA;

E-Mail: caitlin.braitsch@cchmc.org

* Author to whom correspondence should be addressed; E-Mail: katherine.yutzey@cchmc.org; Tel.: +1-513-636-8340; Fax: +1-513-636-5958.

Received: 16 May 2013; in revised form: 19 June 2013 / Accepted: 20 June 2013 /

Published: 3 July 2013

\begin{abstract}
Epicardial derivatives, including vascular smooth muscle cells and cardiac fibroblasts, are crucial for proper development of the coronary vasculature and cardiac fibrous matrix, both of which support myocardial integrity and function in the normal heart. Epicardial formation, epithelial-to-mesenchymal transition (EMT), and epicardium-derived cell (EPDC) differentiation are precisely regulated by complex interactions among signaling molecules and transcription factors. Here we review the roles of critical transcription factors that are required for specific aspects of epicardial development, EMT, and EPDC lineage specification in development and disease. Epicardial cells and subepicardial EPDCs express transcription factors including Wt1, Tcf21, Tbx18, and Nfatc1. As EPDCs invade the myocardium, epicardial progenitor transcription factors such as Wt1 are downregulated. EPDC differentiation into SMC and fibroblast lineages is precisely regulated by a complex network of transcription factors, including Tcf 21 and Tbx18. These and other transcription factors also regulate epicardial EMT, EPDC invasion, and lineage maturation. In addition, there is increasing evidence that epicardial transcription factors are reactivated with adult cardiac ischemic injury. Determining the function of reactivated epicardial cells in myocardial infarction and fibrosis may improve our understanding of the pathogenesis of heart disease.
\end{abstract}

Keywords: transcription factor; Wt1; Tcf21; Tbx18; epicardium derived cell; embryo; cardiovascular disease 


\section{Epicardium-Derived Cells (EPDCs) in Heart Development and Disease}

In the developing heart, cells that form the coronary vessels and the cardiac fibrous matrix are derived from the epicardium and are required for cardiac function [1,2]. Specifically, epicardium-derived cells (EPDCs), generated from the epicardial cell layer by an epithelial-to-mesenchymal transition (EMT), include progenitors of coronary vascular smooth muscle cells (SMCs) and cardiac fibroblasts. Additional Cre-based lineage analysis and cell fate mapping studies provide evidence that EPDCs contribute to vascular endothelial cell and cardiomyocyte lineages [3-7]. Several transcription factors including Wt1, Tcf21, Tbx18, and Nfatc1 have been implicated in epicardial EMT and EPDC lineage development [8-13]. Congenital abnormalities in EPDC lineages can lead to coronary artery anomalies that occur in $1.3 \%$ of the population often resulting in life-threatening arrhythmia, myocardial infarction (MI), or even sudden death [14]. Likewise, epicardium-derived coronary vascular SMCs and cardiac fibroblasts may be reactivated in adult heart disease and cardiac fibrosis [4,15]. Following MI, the epicardium is activated, with new EPDC formation and epicardial transcription factor reactivation suggesting a potential role in adult cardiac injury response, fibrosis, and pathology [16-18]. Thus, there is increasing evidence for recapitulation of epicardial transcriptional developmental regulatory mechanisms in adult cardiovascular disease.

\section{Overview of Epicardial Formation and Cell Lineage Diversification}

In the vertebrate embryo, the proepicardium (PE) is derived from the splanchnic mesoderm and forms as a cluster of mesothelial cells located between the liver and cardiac sinus venosus [19]. Although transient, the PE is significant in that it contributes multiple cell lineages required for heart function, including fibroblasts and coronary smooth muscle (SM) [6,20]. As the primitive heart loops to form the four-chambered heart, the cells of the PE, located at the venous pole of the heart, proliferate and migrate over the myocardium to form the epithelial epicardium [21]. A subset of epicardial cells undergoes EMT and invades the subepicardial space and then the myocardium [20]. Epicardial EMT is evident by embryonic day 11.5 (E11.5) in mice and E3 in chick [22,23]. Following invasion into the myocardium, the majority of progenitor EPDCs differentiates into vascular SMCs, adventitial fibroblasts that support the coronary vasculature, or interstitial fibroblasts that generate the cardiac fibrous matrix $[4,7,19,24]$.

Early retroviral labeling lineage studies and quail-chick chimera experiments indicated that EPDCs contribute to fibroblast, SM, and coronary endothelial cell lineages [1,2]. Subsequent Cre-based fate mapping experiments confirmed epicardial origin of these lineages and also suggested that epicardial derivatives may contribute to cardiomyocytes [3,6,7]. However, the extent to which EPDCs differentiate into coronary endothelium and cardiomyocytes is controversial [3,5-7,25-27]. In the atrioventricular (AV) sulcus, subepicardial mesenchymal cells coalesce to form a primitive capillary plexus, which later remodels to form the mature coronary vasculature [28], and also contributes to the fibrous annulus and parietal AV valve leaflets [24,29,30]. While it is known that multiple cell types arise from epicardial progenitors, the timing and regulation of SMC, fibroblast, and endothelial cell lineage determination is not fully characterized. In addition it is not known if the various epicardial derivatives arise from common or distinct progenitor pools. Recent studies provide evidence that 
EPDC lineages arise from distinct populations located at the venous pole of the heart and are specified prior to epicardial EMT $[6,13]$.

\section{Transcriptional Regulation of Epicardial EMT and EPDC Lineage Specification}

Initial formation of the epicardium, epicardial EMT, and EPDC lineage determination are regulated by a complex network of transcription factors, including the zinc finger transcription factors Wt1, Snai1, and Snai2, as well as the bHLH transcription factors Tcf21, Scleraxis, Twist1, and Hand2 (Figure 1) [8-11]. Additional factors, including Tbx18, Nfatc1, Sox9, and C/EBP, regulate aspects of EPDC lineage development. Signaling pathways and transcription factors together regulate EPDC behavior and differentiation into cardiac fibroblasts and vascular SMCs [4]. Transcription factors expressed in EPDCs, including Wt1, Tbx18, Tcf21, Snai1, and C/EBP, are reactivated in cardiac injury and may mark progenitor or reparative populations in the disease state $[18,31,32]$.

Figure 1. Schematic depicting transcription factor regulation of epicardial cells during embryonic heart development. Several transcription factors are expressed during epicardial epithelial-to-mesenchymal transition (EMT), epicardium-derived cell (EPDC) lineage specification, and EPDC differentiation into vascular smooth muscle cells and cardiac fibroblasts. See text for details and references.

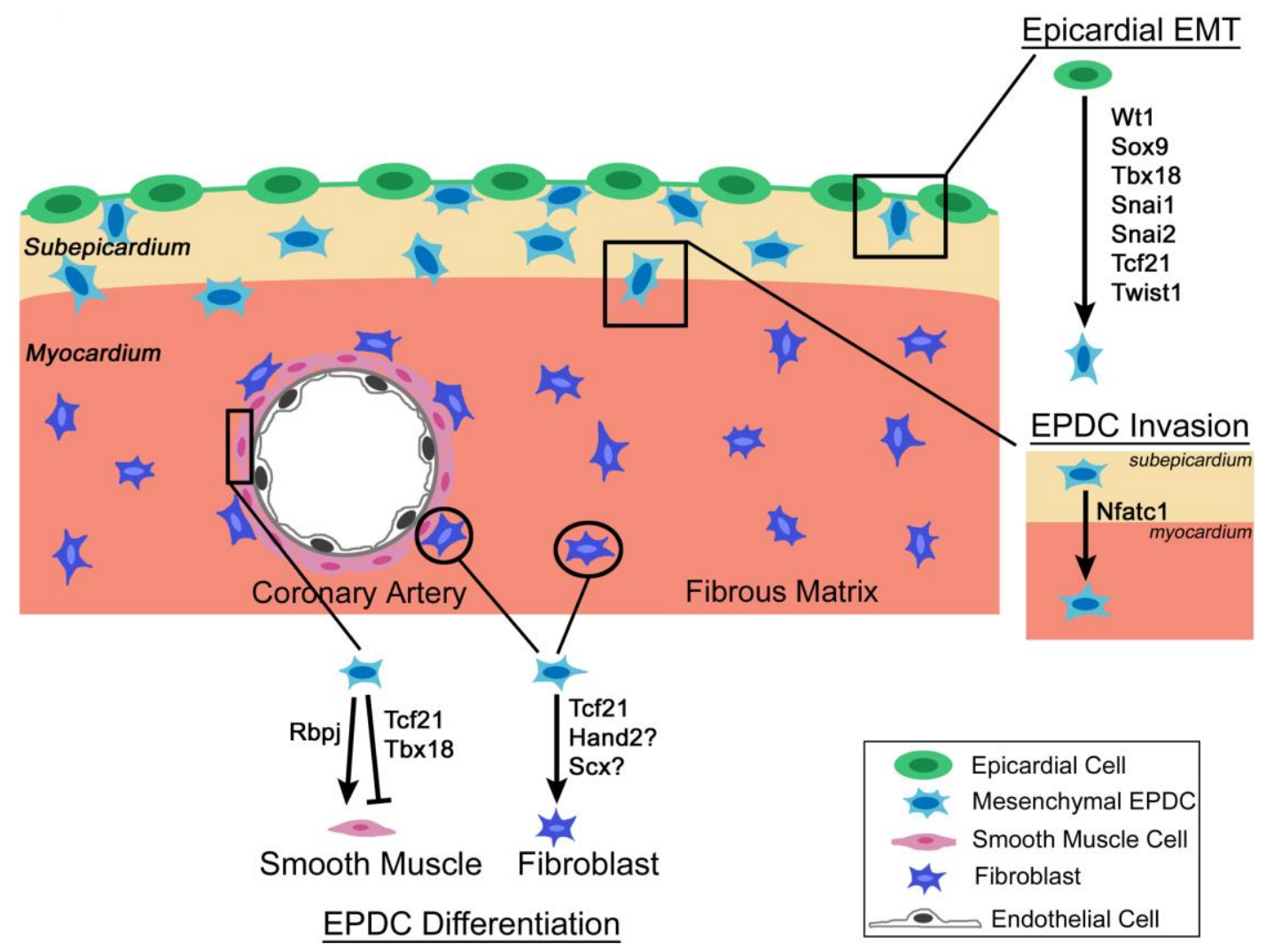

\subsection{Wt1}

The zinc finger transcription factor Wt1 was originally described as a tumor suppressor gene that is mutated in Wilms' tumor patients [33]. Wt1 is robustly expressed in the septum transversum/ pericardial mesothelium, the PE, and the epicardium [34,35]. Following epicardial EMT, Wt1 expression is 
rapidly downregulated in invading EPDCs in the developing heart [36]. Therefore, Wt1 is expressed in EPDC progenitors with expression that diminishes prior to EPDC differentiation. Mice lacking Wt1 have epicardial defects with a paucity of EPDCs, suggesting an EMT defect [12,37,38]. Wt1 is necessary and sufficient to activate transcription of a4integrin (Itga4) via the proximal promoter (Table 1), and Itga4 is required to maintain epicardial adhesion and integrity [11]. In addition, Wt1 directly regulates Snail and Snai2 (Slug) transcription in the epicardium [39,40]. Therefore, Wt1 is a crucial component of the mechanism regulating epicardial adhesion and EMT. Wt1 is required to promote epicardial expression of additional downstream targets, including Nestin, a component of intermediate filaments, TrkB (Tyrosine kinase type B receptor), important for BDNF (brain-derived neurotrophic factor) signaling and vascularization, and Coronin1B, which is crucial for cell motility [41-43]. Thus, loss of Wt1 adversely affects the cytoskeleton, thereby impacting EMT.

Table 1. Transcription factor expression and function in epicardial development (see text for details and references).

\begin{tabular}{|c|c|c|c|}
\hline Gene & Loss-of-function cardiac phenotype ${ }^{a}$ & $\begin{array}{c}\text { Known downstream targets } \\
\text { expressed in EPDCs }\end{array}$ & References \\
\hline Wt1 & $\begin{array}{l}\text { Ventricular non-compaction; impaired } \\
\text { epicardial EMT; impaired coronary plexus } \\
\text { formation; pericardial hemorrhaging; die by } \\
\text { E13.5 }\end{array}$ & $\begin{array}{l}\text { Itga4, Nestin, TrkB, } \\
\text { Coronin1B, Raldh2, Snail, } \\
\text { Snai2 }\end{array}$ & {$[11,12,37-43]$} \\
\hline Tbx18 & $\begin{array}{l}\text { Caval vein defects; sinus horn myocardial } \\
\text { hypoplasia; neonatal lethality }\end{array}$ & Snai2 & {$[40,74,75]$} \\
\hline $\operatorname{Tcf} 21$ & $\begin{array}{l}\text { Aberrant smooth muscle differentiation; loss } \\
\text { of cardiac fibroblasts; pericardial } \\
\text { hemorrhaging; neonatal lethality }\end{array}$ & None identified & {$[8,13,57]$} \\
\hline Nfatc1 & $\begin{array}{l}{ }^{b} \text { Reduced cardiac fibrous matrix with } \\
\text { decreased coronary vessel penetration; } \\
\text { neonatal lethality }\end{array}$ & Ctsk & {$[9,87,88]$} \\
\hline Snail & ${ }^{\mathrm{b}, \mathrm{c}}$ Phenotypically normal and viable & E-cadherin, Mmp 15 & {$[92,93,96,97]$} \\
\hline Snai2 & Phenotypically normal and viable & None identified & {$[40]$} \\
\hline Sox9 & $\begin{array}{l}\text { Hypoplastic endocardial cushions. Embryonic } \\
\text { lethality at E11.5-E12 due to congestive heart } \\
\text { failure. }\end{array}$ & None identified & {$[102,104,108]$} \\
\hline Scleraxis & Thickened valves; viable & Colla2 & {$[106,107]$} \\
\hline $\mathrm{C} / \mathrm{EBP}$ & $\begin{array}{l}{ }^{\mathrm{d}} \text { Improved cardiac function after } \\
\text { ischemia/reperfusion injury }\end{array}$ & Raldh2, Wt1 & {$[32]$} \\
\hline Hand2 & $\begin{array}{l}{ }^{\mathrm{e}} \text { Epicardial blistering; abnormal coronary } \\
\text { vessel development; loss of cardiac } \\
\text { fibroblasts; persistent truncus arteriosus. } \\
\text { Embryonic lethality by E14.5. }\end{array}$ & Pdgfra & [101] \\
\hline Twist1 & $\begin{array}{l}\text { Abnormal outflow tract endocardial cushion } \\
\text { mesenchyme. Embryonic lethality by E11.5. }\end{array}$ & Tbx20, Snai2 & {$[30,76,100]$} \\
\hline
\end{tabular}

\footnotetext{
${ }^{a}$ Described phenotypes are due to knockout mouse models, except in cases of epicardial-specific gene deletion, as indicated; Gene (floxed allele) was deleted from the ${ }^{\mathrm{b}} \mathrm{Wt} 1 \mathrm{Cre},{ }^{\mathrm{c}} \mathrm{Tbx} 18 \mathrm{Cre}$, or ${ }^{\mathrm{e}} \mathrm{Hand} 1 \mathrm{Cre}$ lineages, as indicated; ${ }^{\mathrm{d}}$ Antisense adenoviral-mediated knockdown.
} 
Multiple signaling pathways required for EPDC lineage development are affected with loss of Wt1. Retinoic acid (RA) signaling is required during cardiac morphogenesis [44]. Retinoid X Receptor $\alpha$, which binds RA in the nucleus, is required during cardiac development, as Rxr $\alpha$ null mice are embryonic lethal by E15 with ventricular hypoplasia and delayed formation of the epicardium [45-47]. Wt1-deficient embryos have decreased expression of Retinaldehyde dehydrogenase-2 (Raldh2), a direct downstream target of Wt1, and epicardial EMT is partially rescued by RA supplementation in Wt1-deficient embryos [12,37]. Interestingly, RA induces Wt1 expression in proepicardial cells and EPDCs in cell culture supporting a feedforward regulatory mechanism [8]. Canonical Wnt/ $\beta$-Catenin signaling, required for epicardial EMT, ventricular compaction, and formation of the coronary plexus in mouse embryonic hearts, also is downstream of Wt1 [12,48,49]. In Wt1 null embryos, the epicardium fails to undergo EMT and Wnt signaling is reduced $[12,48,49]$. Therefore, Wt1 is a master regulator upstream of crucial signaling pathways, including Wnt/ $\beta$-Catenin and RA, in epicardial development. In addition, Wt1, Wnt/ $\beta$-Catenin, and Raldh 2 are reactivated in mouse models of adult heart disease, including MI, ischemia/reperfusion (I/R), and pressure overload (Figure 2) [16,18,31,50].

Initial Wt1Cre-based lineage studies reported that the majority of Wt1-derived cells differentiate into SM, but that some Wt1-derived cells differentiate into cardiomyocytes and endothelial cells [7]. Wt1 lineage-derived cells also contribute to fibroblasts of the annulus fibrosis, interstitial fibroblasts, and AV valve parietal leaflet interstitial cells [24,30]. Very few, if any, endothelial cells are derived from the Wt1 lineage in these analyses [7,24,30]. The report that Wt1 lineage-positive cells become cardiomyocytes, thereby supporting an epicardial origin for cardiac muscle, is controversial [51,52]. Caveats to this approach are that $\mathrm{Wt} 1$ expression is not completely epicardial-specific in addition to potential leakiness of Cre expression and inefficiency of recombination inherent to the Wt1Cre mouse lines [51,52]. Tamoxifen-inducible Wt1Cre lines add temporal and spatial specificity, but inefficient and variable recombination following tamoxifen induction is a concern with the Wt1CreERT2 mouse line [51,52]. It remains controversial whether small subpopulations of Wt1 lineage-positive epicardial cells become cardiomyocytes or endothelial cells. However, there is general agreement that the majority of Wt1Cre-positive epicardial derivatives become fibroblasts and vascular SMCs [7,24,51].

\section{2. $\operatorname{Tcf} 21$}

The bHLH transcription factor Tcf21 (Pod1/Epicardin/Capsulin) is expressed in developing mesothelial cell populations, including the PE and epicardium, as well as kidney, lung, and reproductive tract [53-55]. Loss of Tcf21 leads to kidney and lung defects, spleen agenesis, and neonatal lethality [56,57]. In the heart, Tcf2 1 is required for normal epicardial development and regulates EPDC differentiation into $\mathrm{SM}$ and fibroblast lineages [8,13]. Tcf21 deficiency leads to aberrant SM differentiation in the subepicardial mesenchyme and a paucity of cardiac fibroblasts in the myocardial interstitium [8]. Expression of Tcf21, like Wt1, is induced by RA signaling in EPDCs, and RA inhibits SM differentiation of PE derivatives [8,58]. Tcf21 expression is downregulated in differentiated vascular SM in the myocardial interstitium, consistent with a repressive role in the differentiation of this lineage. Thus, Tcf21 and RA signaling together inhibit SM gene expression and differentiation in EPDC progenitor cells prior to their localization in the coronary vasculature. In contrast, Tcf2 1 expression promotes cardiac fibroblast identity and persists in differentiated cardiac interstitial and adventitial fibroblasts in the postnatal and adult heart $[8,13,59]$. 
Figure 2. Model depicting epicardial cell reactivation and expression of transcription factors, including Tcf21, Wt1, Tbx18, Snail, and C/EBP $\beta$, following myocardial infarction (MI) in the adult heart. Activated epicardial cells undergo EMT and invade the subepicardial space following MI. The ultimate fate of activated EPDCs and their ability to invade the myocardium in the infarcted heart has not yet been fully characterized. In the area of the infarct scar Tcf21, Wt1, Tbx18, and Scleraxis (Scx) also are expressed, and immune cells are present in the activated epicardium and fibrotic scar. Currently, it has not been reported whether epicardial transcription factors are activated in other forms of cardiac fibrosis. See text for details and references.

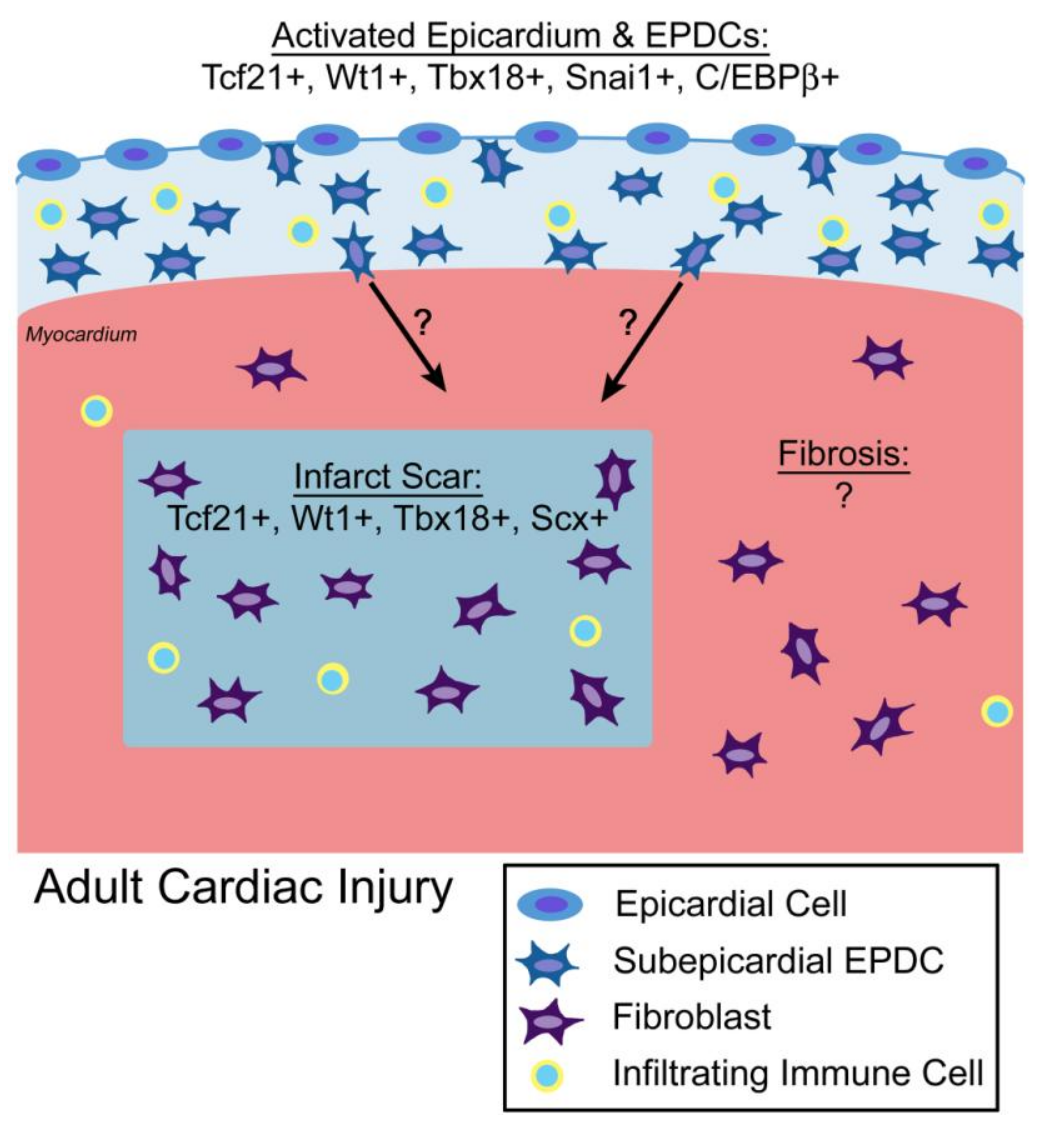

Tcf21 heterodimerizes with the class I bHLH transcription factor E12 [60,61]. Together, Tcf21 and E12 negatively regulate transcription [60,62]. Analysis of Xenopus embryos indicates that Tcf21 functions as a transcriptional repressor with other repressor proteins to regulate PE-specific gene expression [63]. Additional bHLH dimerization partners for Tcf21 have not been described, nor have Tcf21 downstream targets been identified in the heart in vivo. Studies using a mesenchymal cell line derived from adult mouse kidney determined that Tcf 21 binds to E-box DNA consensus sequences (CAnnTG) in the SM22 $\alpha$, Calponin, and $\alpha S M A$ promoters [64]. Overexpression of Tcf21 alone leads to decreased expression of SM22 $\alpha$, Calponin, and $\alpha$ SMA protein, whereas overexpression of Tcf 21 and E2A results in increased SM22 $\alpha$, Calponin, and $\alpha$ SMA protein expression [64]. Therefore, expression of E2A, which encodes the E12 and E47 transcription factors, may influence the role of Tcf21 in terms of SM and myofibroblast downstream targets [65]. In addition to acting as a transcriptional repressor, Tcf21 contains an activation domain at its C-terminus [66,67]. While 
expression of SM22 $\alpha$, Calponin, and $\alpha \mathrm{SMA}$ is increased in Tcf21 null hearts [8], direct regulatory interactions of Tcf 21 with these gene regulatory elements have not yet been established in EPDCs. The dynamic and differential mechanisms by which Tcf21 regulates cell fate have yet to be determined. Likewise, the identity of Tcf2 1 E-box binding partners is likely to influence Tcf2 1 function in different contexts [62].

Fate mapping studies with the tamoxifen-inducible Tcf21iCre mouse line demonstrate that Tcf21iCre-derived cells contribute to fibroblasts of the coronary adventitia and myocardial interstitium, in addition to coronary vascular SMCs, when Cre activity is induced during embryogenesis [59]. In addition, Tcf21iCre-derived cells are detected in the gonads, lung, spleen, adrenal gland, and facial skeletal muscles [59]. Interestingly, in the heart, lung, kidney, spleen, adrenal gland, testes, and ovaries, Tcf 21 iCre-derived cells contribute to interstitial cells that support organ function [59]. Therefore, Tcf21 regulation of interstitial fibroblast formation may be conserved throughout the developing embryo. In the heart, fate mapping of the embryonic Tcf2 1 lineage marks fibroblasts and SMCs, but not cardiomyocytes or endothelial cells [59,68]. Postnatal induction of Tcf21iCre activity leads to recombination in cardiac interstitial cells, but not endothelial cells, supporting a homeostatic role for Tcf21 in fibroblast lineages after birth [59]. As determined by genome-wide association studies of human coronary artery disease (CAD), a variant of TCF21 is associated with increased risk of CAD in European and Chinese Han populations [69,70]. Likewise, TCF21 is expressed in human cardiac fibrotic disease and ischemic cardiomyopathy ([71]; Braitsch, unpublished). In addition, Tcf21 is reactivated following myocardial injury in adult mouse and zebrafish models (Figure 2) $[15,16,18,31,68]$. Therefore, Tcf21 is likely to play an important role in adult cardiac homeostasis and disease.

\section{3. $T b x 18$}

Tbx18, a member of the T-box transcription factor family, is expressed in the PE, epicardium, somites, limb buds, and genital ridge [72,73]. Mice lacking Tbx18 die at birth due to cyanosis resulting from severe defects of the axial skeleton $[10,74]$. In the heart, Tbx18 contributes to, and is required for, formation of the sinus horn myocardium at the venous pole of the heart [75]. Loss of Tbx18 does not appear to affect epicardial development, as EPDCs are apparently unaffected in the $T b \times 18^{-/-}$mouse heart [74]. It is possible that Tbx20, which is expressed in the epicardium and subepicardial EPDCs, may have overlapping or redundant functions with Tbx18 in these cells [76]. Lineage-tracing analysis of a Tbx18Cre knock-in allele indicates that cells from the Tbx18Cre lineage differentiate into fibroblasts, vascular SMCs, and cardiomyocytes [3]. However, Tbx18 is actively expressed in myocardium of the interventricular septum and left ventricle during mouse embryogenesis from E10.5-E16.5, supporting a nonepicardial source for Tbx18 lineage-positive cardiomyocytes [75,77]. In contrast, studies by multiple groups confirm that vascular SM and cardiac fibroblasts, but not endothelial cells, arise from a Tbx18-positive epicardial lineage [3,77,78].

T-box transcription factors can act as transcriptional activators and/or repressors [73]. In the developing somites, Tbx18 maintains anterior somite identity by acting as a transcriptional repressor of Delta-like 1 (Dll1), a Notch effector [79]. In EPDCs, there is evidence that Tbx18 functions as a transcriptional repressor of SM differentiation, since ectopic expression of a transcriptional activator 
Tbx18VP16 leads to premature SM differentiation in the epicardium [10]. Tbx18VP16-mediated SM differentiation in epicardial cells is reversed by Notch inhibition in vitro [10]. However, few cardiac-specific downstream targets of Tbx18 have been identified. Tbx18 directly binds and promotes epicardial Snai2 expression, thereby promoting epicardial EMT in cell culture [40]. Together these studies indicate that Tbx18 maintains progenitor cell identity by acting as a transcriptional repressor during embryonic development, often upstream of Notch signaling. In addition, Tbx18 is reactivated in epicardial cells in adult ischemic heart disease (Figure 2) [16,31].

\subsection{Nfatc1}

Nfatc 1 is a member of the nuclear factor of activated T cells family of transcription factors, which are activated and localized to the nucleus by $\mathrm{Ca}^{2+}$ signaling via the calcium-responsive phosphatase calcineurin [80]. Loss of Nfatc1 in mice leads to lethality at E12.5-E14.5 with defects in heart valve remodeling [81,82]. Nfatc1 is expressed in the endocardial cushions and remodeling heart valves, as well as in the PE, epicardium, and EPDCs during heart development $[9,83,84]$. In the developing valves, Nfatcl is required to promote endocardial cushion proliferation through the VEGF pathway and to regulate heart valve remodeling via Receptor Activator of Nuclear factor Kappa-B Ligand (RANKL) signaling [83,85,86]. In EPDCs, Nfatc1 is required for invasion of the myocardium, and mice deficient in epicardial Nfatcl have decreased interstitial fibrous matrix deposition and exhibit neonatal lethality [9]. Likewise, epicardial loss of Nfatc1 results in decreased coronary vessel penetration, without affected SM differentiation, in the embryonic mouse heart [9]. Specifically, epicardial Nfatcl is necessary for RANKL promotion of CathepsinK (Ctsk) mediated EPDC invasion of the myocardium [9]. Ctsk is an ECM remodeling enzyme that facilitates cell migration and is a transcriptional target of Nfatc1 (Table 1), first defined in osteoclast cell lineages [87,88]. Therefore, Nfatc1 is required for Ctsk expression and cell invasion, necessary for EPDC lineage development, in a mechanism that also is active in developing osteoclasts and remodeling heart valves.

Nfatc 1 also has been implicated in coronary endothelial lineage development. Nfatc1 is expressed in differentiated coronary endothelial cells, and calcineurin/NFAT signaling is required for coronary angiogenesis during embryonic heart development [9,89]. Targeted deletion of Nfatc1 with Wt1Cre or Gata5Cre does not prevent differentiation of coronary endothelial cells, but these Cre lines are not generally considered to be active in the endothelial lineage [9,51]. However, calcineurin/NFAT signaling is required in endothelial cells for coronary vessel development and is induced by VEGF signaling [89]. Recently, endocardial endothelial cells were reported to be a source of coronary endothelial cells based on restriction of Nfatc1 expression to the endocardium [27]. While these data do not take into account Nfatcl expression in the epicardium and its necessity for EPDC invasion, they do support multiple sources of coronary endothelial cells that warrant further investigation [6,9,27]. In addition, the specific functions and downstream targets of Nfatc1 in coronary endothelial cell differentiation have not been identified.

\subsection{Snail and Snal2}

The zinc finger transcription factors Snail (Snail1) and Snai2 (Snail2, Slug) are robustly expressed in the epicardium and EPDCs of mouse and chick embryonic hearts [90,91]. Snail promotes EMT in 
the endocardial cushions as well as in other organ systems and during tumorigenesis, in part via the Snail downstream target Mmp15 [92,93]. However, there is conflicting evidence for the requirement for Snail and Snai2 in epicardial EMT [39,90,94]. In cultured avian epicardial cells, Snail overexpression promotes cell migration and invasion [94]. Similarly in mouse epicardial cell cultures, loss of Snai2 inhibits EMT, and Snai2 gene expression is dependent on Wt1 and Tbx18 [40]. Deletion of Wt1 from the more broadly expressed Gata5Cre lineage leads to loss of Snail expression with concomitant epicardial EMT defects with embryonic lethality $[39,95]$. In contrast, in vivo loss of Snai1 in Wt1Cre or Tbx18Cre lineages does not affect epicardial EMT or differentiation [90]. In a variety of cell types, Snail represses expression of E-cadherin and other adhesion molecules, which are required to maintain epithelial integrity $[96,97]$. Wt1Cre-mediated loss of the Notch pathway transcriptional activator Rbpj leads to decreased expression of Snail, consistent with an observed EMT defect, as well as aberrant coronary SM differentiation [98]. Together these studies suggest that Notch signaling regulates Snail and E-cadherin, both of which affect epicardial EMT. This same regulatory hierarchy also is active in endocardial cushion EMT [99]. In addition, Snail expression is reactivated in the infarct scar following MI (Figure 2) [31].

\subsection{Twist1 and Hand2}

In addition to Tcf21, the bHLH transcription factors Twist 1 and Hand2 also have been implicated in EPDC development. Twist1 is expressed in EPDCs of avian embryos at the same time it is expressed in endocardial cushions, where it promotes mesenchymal cell proliferation and migration [76]. In mice, EPDCs isolated from mouse AV canals express Twist1, in addition to Snai1, Snai2, and Smad1 markers of EMT [30]. However, a specific function for Twist 1 in the epicardium or EPDCs has not yet been demonstrated. In endocardial cushions, Twist 1 promotes expression of genes associated with cell proliferation and migration, and a similar regulatory mechanism may be active in EPDCs [76,100]. For example, Tbx20 is expressed in EPDCs as well as endocardial cushions and is a direct downstream target of Twist1 in endocardial cushion cells [76,100]. Likewise, Hand1 is expressed at the venous pole of the heart and cells of the Hand1 lineage contribute to epicardial progenitors [101]. In addition, loss of Hand2 in the Hand1 lineage leads to epicardial blistering, abnormal coronary vessel development, and loss of cardiac fibroblasts [101]. Hand2 promotes expression of Pdgfra, which is required for epicardial EMT and epicardium-derived cardiac fibroblasts [101,102]. Additional studies are necessary to define the specific functions and transcriptional targets of Twist1, Hand1, and Hand2 in epicardial lineage development.

\subsection{Scleraxis and Sox9}

Scleraxis (Scx) is a bHLH transcription factor originally reported to be important in tendon development, and it also functions in cell lineage diversification in heart valvulogenesis [103-105]. Scx is expressed in a subdomain of the mouse PE, beginning at E9.5, and in the epicardium at E10.5 [6]. In the PE, cells that express Scx do not express Wt1 or Tbx18, demonstrating heterogeneity of this progenitor population [6]. ScxCre-derived cells contribute to coronary endothelial cells on the surface of the heart and also to cardiomyocytes in the LV. However, ScxCre-positive cells are rarely detected in SM at E12.5, in contrast to Wt1Cre or Tbx18Cre-derived cells, providing evidence for distinct 
compartments of proepicardial cells that give rise to endothelial versus fibroblast and SM lineages. The specific function(s) of Scx in epicardial development has not been demonstrated, although loss of Scx leads to persistent expression of EMT markers and heart valve remodeling defects at E17.5 in mice [106]. Interestingly, in adult $\mathrm{Scx}^{-/}$mice, thickening and increased collagen deposition are apparent in the AV annulus and mitral valve parietal leaflet that are derived from epicardium $[24,30,106]$. In adult cardiac fibroblasts, Scx directly regulates Colla2 gene expression, and Scx expression also is induced after MI, supporting a role in cardiac fibrosis (Figure 2) [107]. However, additional studies are necessary to define the specific functions of Scx in epicardium-derived cell lineage development or pathogenesis related to EPDCs.

Sox9 is an SRY-related transcription factor that is crucial for heart valve development [104]. During valvulogenesis, Sox9 is required for endocardial cushion EMT, progenitor cell proliferation, and proteoglycan-rich cell lineage development [104,108]. Sox9 also is expressed in EPDCs and is sufficient to promote epicardial EMT and migration [102]. Therefore, mechanisms regulating EMT and mesenchymal proliferation may be conserved in endocardial cushions and epicardium. However, little is known of Sox9 functions in EPDCs, and defective EPDC lineage development has not been reported in Sox9-deficient mouse embryos.

\section{8. $C / E B P$}

In a recent report, CCAAT/enhancer binding proteins (C/EBPs) were identified as critical transcriptional regulators of epicardial gene expression during development, that are also activated after cardiac injury [32]. Analysis of conserved enhancer regions of Raldh2 and Wt1 revealed the presence of multiple $\mathrm{C} / \mathrm{EBP}$ binding sites required for epicardial expression of both genes during embryonic development. In adult mice, epicardial $\mathrm{C} / \mathrm{EBP} \beta$ expression is activated with cardiac ischemic injury (Figure 2), and $\mathrm{C} / \mathrm{EBP}$ function is required for epicardial $W t 1$ and Raldh2 gene activation. Loss of C/EBP function with cardiac ischemic injury leads to reduced fibrosis, decreased inflammation, and improved cardiac function. C/EBPs likely act with other epicardially expressed transcription factors in yet unidentified regulatory hierarchies in EPDC development and response to cardiac injury.

\section{Transcriptional Regulation of EPDC Lineages in Adult Cardiac Regeneration, Injury, and Fibrosis}

Adult zebrafish, unlike adult mammals, have the ability to regenerate cardiac muscle after resection or cryoinjury [109,110]. Epicardial activation, evident in increased Raldh2, Wt1, Tbx18, and Tcf21 expression and increased cellularity of the epicardium, occurs with injury in adult zebrafish $[68,111,112]$. However, the new muscle arises from existing cardiomyocytes during the regenerative process $[113,114]$. Fate mapping of Tcf21-positive epicardial cells demonstrates that they contribute to perivascular cells, but not cardiomyocytes, during regeneration [68]. Epicardial contributions to the regenerate were not observed, although Raldh2 expression was increased, indicative of epicardial activation with injury [111]. The role of epicardial activation and specific functions of transcription factors in the activated epicardium are not known; however, RA signaling emanating from the epicardium and endocardium is required for regeneration [111]. Since Raldh2 is a downstream target of Wt1 in mouse embryo EPDCs, 
a similar regulatory interaction may be conserved in zebrafish regeneration. In mice, neonates can renegerate myocardium after ventricular resection, but this ability is lost by postnatal day 7 [115]. Wt1 and Raldh2 expression is increased in the neonatal mouse epicardium after injury, but proliferation of existing cardiomyocytes was observed to be the source of regenerated myocardium. Together, studies in zebrafish and neonatal mice demonstrate a potential indirect inductive role for EPDC activation in cardiac regeneration and revascularization, but do not support direct EPDC contributions to new cardiomyocyte populations.

In adult humans and mice, EPDC transcriptional programs are reactivated with cardiac injury and fibrosis. Epicardial expression of Wt1, Tcf21, Tbx18, and Raldh2 is increased after MI in mice and in human diseased hearts $[16,18,31,71,116]$. In addition, increased numbers of cells, that include EPDCs and infiltrating immune cells, are present in the subepicardial space (Figure 2) [18]. Indicators of EMT, including Wnt/ $\beta$-catenin signaling, Notch signaling, and Snail expression, are induced, consistent with reactivation of epicardial cells and generation of new EPDCs of unknown fate or function [18,31,50,71,117]. Fate mapping studies of the tamoxifen-inducible Wt1CreER lineage demonstrated that the activated EPDCs that express Wt1 become fibroblasts and SM cells, but not cardiomyocytes or endothelial cells, after MI in mice [18]. Increased EPDC expression of proangiogenic factors also was observed in these studies, but it is not clear if these genes are directly regulated by EPDC transcription factors such as Wt1, Tcf21, or Tbx18 that also are induced with MI [18]. In addition to subepicardial cells and EPDCs, Wt1, Tcf21, and Tbx18 also are expressed in interstitial and perivascular fibrotic regions of human and mouse diseased heart, but the functions of these factors in cardiac fibrosis and origins of these cells have not yet been determined ([18,31]; Braitsch, unpublished). While it is clear that transcription factors expressed in embryonic EPDCs also are expressed in the adult epicardium with cardiac injury and fibrotic regions of diseased hearts, additional research is necessary to determine their specific regulatory mechanisms and potential therapeutic applications in human cardiovascular disease.

\section{Conclusions and Future Perspectives}

Since the initial reports of EPDCs in the 1990s, there have been rapid discoveries of transcription factors and signaling pathways important for epicardium-derived cell lineage development. More recently, epicardial transcription factor expression has been reported in adult cardiac disease. While EPDC transcription factors have been used as markers for progenitor cells and epicardial activation, specific information related to transcriptional targets and cell lineage regulation is limited. Much is yet to be learned in terms of transcriptional regulatory networks and lineage determination mechanisms in the developing epicardium and its derivatives. Interestingly, epicardial transcription factors, including Wt1, Tcf21, and Tbx18, also are expressed in a variety of mesothelial progenitor lineages, and it is likely that they have similar roles in fibroblast and SM development in multiple organs. Intersection with Notch, RA, and Wnt signaling pathways also may be conserved in the development of these lineages. Transcription factors expressed in the epicardium prior to or during the generation of EPDCs are in many cases also expressed once EPDCs reach their final destination in the heart and differentiate into fibroblasts and SMCs. Thus, it seems likely that there will be more than one function for these factors depending on timing (epicardium versus EPDC) and environment (surface, myocardial 
interstitium, coronary vessel). Even less is known of activated EPDC function and transcriptional regulatory mechanisms in adult cardiovascular disease. There has been much recent excitement and high impact research in this area, but specific pathologic or reparative functions of EPDCs and associated transcription factors are yet to be fully defined. While it is possible that EPDCs contribute to cardiac repair, especially in the promotion of vascularization, it seems very likely that EPDCs also contribute to pathological fibrosis and, potentially, heart failure. Thus, efforts directed towards harnessing EPDCs in the treatment of human cardiovascular disease should proceed with caution.

\section{Acknowledgments}

We thank members of the Yutzey lab for critical reading of the manuscript. Grant support was provided by NIH/NHLBI HL082716, HL094319, and HL069779 to K.E.Y.

\section{Conflict of Interest}

The authors declare no conflict of interest.

\section{References}

1. Gittenberger-de Groot, A.C.; Vrancken Peeters, M.P.; Mentink, M.M.; Gourdie, R.G.; Poelmann, R.E. Epicardium-derived cells contribute a novel population to the myocardial wall and the atrioventricular cushions. Circ. Res. 1998, 82, 1043-1052.

2. Mikawa, T.; Gourdie, R.G. Pericardial mesoderm generates a population of coronary smooth muscle cells migrating into the heart along with ingrowth of the epicardial organ. Dev. Biol. 1996, 174, 221-232.

3. Cai, C.L.; Martin, J.C.; Sun, Y.; Cui, L.; Wang, L.; Ouyang, K.; Yang, L.; Bu, L.; Liang, X.; Zhang, X.; et al. A myocardial lineage derives from Tbx18 epicardial cells. Nature 2008, 454, 104-108.

4. Gittenberger-de Groot, A.C.; Winter, E.M.; Poelmann, R.E. Epicardium-derived cells (EPDCs) in development, cardiac disease and repair of ischemia. J. Cell. Mol. Med. 2010, 14, 1056-1060.

5. Red-Horse, K.; Ueno, H.; Weissman, I.L.; Krasnow, M.A. Coronary arteries form by developmental reprogramming of venous cells. Nature 2010, 464, 549-553.

6. Katz, T.C.; Singh, M.K.; Degenhardt, K.; Rivera-Feliciano, J.; Johnson, R.L.; Epstein, J.A.; Tabin, C.J. Distinct compartments of the proepicardial organ give rise to coronary vascular endothelial cells. Dev. Cell 2012, 22, 639-650.

7. Zhou, B.; Ma, Q.; Rajagopal, S.; Wu, S.M.; Domian, I.; Rivera-Feliciano, J.; Jiang, D.; von Gise, A.; Ikeda, S.; Chien, K.R.; et al. Epicardial progenitors contribute to the cardiomyocyte lineage in the developing heart. Nature 2008, 454, 109-113.

8. Braitsch, C.M.; Combs, M.D.; Quaggin, S.E.; Yutzey, K.E. Pod1/Tcf21 is regulated by retinoic acid signaling and inhibits differentiation of epicardium-derived cells into smooth muscle in the developing heart. Dev. Biol. 2012, 368, 345-357.

9. Combs, M.D.; Braitsch, C.M.; Lange, A.W.; James, J.F.; Yutzey, K.E. Nfatc1 promotes epicardium-derived cell invasion into myocardium. Development 2011, 138, 1747-1757. 
10. Greulich, F.; Farin, H.F.; Schuster-Gossler, K.; Kispert, A. Tbx18 function in epicardial development. Cardiovasc. Res. 2012, 96, 476-483.

11. Kirschner, K.M.; Wagner, N.; Wagner, K.D.; Wellmann, S.; Scholz, H. The Wilms tumor suppressor Wt1 promotes cell adhesion through transcriptional activation of the alpha4integrin gene. J. Biol. Chem. 2006, 281, 31930-31939.

12. von Gise, A.; Zhou, B.; Honor, L.B.; Ma, Q.; Petryk, A.; Pu, W.T. Wt1 regulates epicardial epithelial to mesenchymal transition through beta-catenin and retinoic acid signaling pathways. Dev. Biol. 2011, 356, 421-431.

13. Acharya, A.; Baek, S.T.; Huang, G.; Eskiocak, B.; Goetsch, S.; Sung, C.Y.; Banfi, S.; Sauer, M.F.; Olsen, G.S.; Duffield, J.S.; et al. The bHLH transcription factor Tcf21 is required for lineage-specific EMT of cardiac fibroblast progenitors. Development 2012, 139, 2139-2149.

14. Kayalar, N.; Burkhart, H.M.; Dearani, J.A.; Cetta, F.; Schaff, H.V. Congenital coronary anomalies and surgical treatment. Congenit. Heart Dis. 2009, 4, 239-251.

15. Smart, N.; Bollini, S.; Dube, K.N.; Vieira, J.M.; Zhou, B.; Davidson, S.; Yellon, D.; Riegler, J.; Price, A.N.; Lythgoe, M.F.; et al. De novo cardiomyocytes from within the activated adult heart after injury. Nature 2011, 474, 640-644.

16. Limana, F.; Bertolami, C.; Mangoni, A.; Di Carlo, A.; Avitabile, D.; Mocini, D.; Iannelli, P.; DeMori, R.; Marchetti, C.; Pozzoli, O.; et al. Myocardial infarction induces embryonic reprogramming of epicardial c-kit(+) cells: Role of the pericardial fluid. J. Mol. Cell. Cardiol. 2010, 48, 609-618.

17. Smart, N.; Riley, P.R. The epicardium as a candidate for heart regeneration. Future Cardiol. 2012, 8, 53-69.

18. Zhou, B.; Honor, L.B.; He, H.; Ma, Q.; Oh, J.H.; Butterfield, C.; Lin, R.Z.; Melero-Martin, J.M.; Dolmatova, E.; Duffy, H.S.; et al. Adult mouse epicardium modulates myocardial injury by secreting paracrine factors. J. Clin. Invest. 2011, 121, 1894-1904.

19. Munoz-Chapuli, R.; Macias, D.; Gonzalez-Iriarte, M.; Carmona, R.; Atencia, G.; Perez-Pomares, J.M. [the epicardium and epicardial-derived cells: Multiple functions in cardiac development]. Rev. Esp. Cardiol. 2002, 55, 1070-1082.

20. Lie-Venema, H.; van den Akker, N.M.; Bax, N.A.; Winter, E.M.; Maas, S.; Kekarainen, T.; Hoeben, R.C.; de Ruiter, M.C.; Poelmann, R.E.; Gittenberger-de Groot, A.C. Origin, fate, and function of epicardium-derived cells (EPDCs) in normal and abnormal cardiac development. ScientificWorldJournal 2007, 7, 1777-1798.

21. Reese, D.E.; Mikawa, T.; Bader, D.M. Development of the coronary vessel system. Circ. Res. 2002, 91, 761-768.

22. Lavine, K.J.; Ornitz, D.M. Fibroblast growth factors and hedgehogs: At the heart of the epicardial signaling center. Trends Genet. 2008, 24, 33-40.

23. Winter, E.M.; Gittenberger-de Groot, A.C. Epicardium-derived cells in cardiogenesis and cardiac regeneration. Cell. Mol. Life Sci. 2007, 64, 692-703.

24. Wessels, A.; van den Hoff, M.J.; Adamo, R.F.; Phelps, A.L.; Lockhart, M.M.; Sauls, K.; Briggs, L.E.; Norris, R.A.; van Wijk, B.; Perez-Pomares, J.M.; et al. Epicardially derived fibroblasts preferentially contribute to the parietal leaflets of the atrioventricular valves in the murine heart. Dev. Biol. 2012, 366, 111-124. 
25. Kispert, A. No muscle for a damaged heart: Thymosin beta 4 treatment after myocardial infarction does not induce myocardial differentiation of epicardial cells. J. Mol. Cell. Cardiol. 2012, 52, 10-12.

26. Perez-Pomares, J.M.; Carmona, R.; Gonzalez-Iriarte, M.; Atencia, G.; Wessels, A.; MunozChapuli, R. Origin of coronary endothelial cells from epicardial mesothelium in avian embryos. Int. J. Dev. Biol. 2002, 46, 1005-1013.

27. Wu, B.; Zhang, Z.; Lui, W.; Chen, X.; Wang, Y.; Chamberlain, A.A.; Moreno-Rodriguez, R.A.; Markwald, R.R.; O'Rourke, B.P.; Sharp, D.J.; et al. Endocardial cells form the coronary arteries by angiogenesis through myocardial-endocardial VEGF signaling. Cell 2012, 151, 1083-1096.

28. Mu, H.; Ohashi, R.; Lin, P.; Yao, Q.; Chen, C. Cellular and molecular mechanisms of coronary vessel development. Vasc. Med. 2005, 10, 37-44.

29. Lie-Venema, H.; Eralp, I.; Markwald, R.R.; van den Akker, N.M.; Wijffels, M.C.; Kolditz, D.P.; van der Laarse, A.; Schalij, M.J.; Poelmann, R.E.; Bogers, A.J.; et al. Periostin expression by epicardium-derived cells is involved in the development of the atrioventricular valves and fibrous heart skeleton. Differentiation 2008, 76, 809-819.

30. Zhou, B.; von Gise, A.; Ma, Q.; Hu, Y.W.; Pu, W.T. Genetic fate mapping demonstrates contribution of epicardium-derived cells to the annulus fibrosis of the mammalian heart. Dev. Biol. 2010, 338, 251-261.

31. van Wijk, B.; Gunst, Q.D.; Moorman, A.F.; van den Hoff, M.J. Cardiac regeneration from activated epicardium. PLoS One 2012, 7, e44692.

32. Huang, G.N.; Thatcher, J.E.; McAnally, J.; Kong, Y.; Qi, X.; Tan, W.; DiMaio, J.M.; Amatruda, J.F.; Gerard, R.D.; Hill, J.A.; et al. C/EBP transcription factors mediate epicardial activation during heart development and injury. Science 2012, 338, 1599-1603.

33. Huff, V.; Miwa, H.; Haber, D.A.; Call, K.M.; Housman, D.; Strong, L.C.; Saunders, G.F. Evidence for WT1 as a Wilms tumor (WT) gene: Intragenic germinal deletion in bilateral WT. Am. J. Hum. Genet. 1991, 48, 997-1003.

34. Armstrong, J.F.; Pritchard-Jones, K.; Bickmore, W.A.; Hastie, N.D.; Bard, J.B. The expression of the Wilms' tumour gene, WT1, in the developing mammalian embryo. Mech. Dev. 1993, 40, 85-97.

35. Carmona, R.; Gonzalez-Iriarte, M.; Perez-Pomares, J.M.; Munoz-Chapuli, R. Localization of the Wilm's tumour protein WT1 in avian embryos. Cell Tissue Res. 2001, 303, 173-186.

36. Perez-Pomares, J.M.; Phelps, A.; Sedmerova, M.; Carmona, R.; Gonzalez-Iriarte, M.; MunozChapuli, R.; Wessels, A. Experimental studies on the spatiotemporal expression of WT1 and RALDH2 in the embryonic avian heart: A model for the regulation of myocardial and valvuloseptal development by epicardially derived cells (EPDCs). Dev. Biol. 2002, 247, 307-326.

37. Guadix, J.A.; Ruiz-Villalba, A.; Lettice, L.; Velecela, V.; Munoz-Chapuli, R.; Hastie, N.D.; Perez-Pomares, J.M.; Martinez-Estrada, O.M. Wt1 controls retinoic acid signalling in embryonic epicardium through transcriptional activation of raldh2. Development 2011, 138, 1093-1097.

38. Moore, A.W.; McInnes, L.; Kreidberg, J.; Hastie, N.D.; Schedl, A. YAC complementation shows a requirement for $\mathrm{Wt} 1$ in the development of epicardium, adrenal gland and throughout nephrogenesis. Development 1999, 126, 1845-1857. 
39. Martinez-Estrada, O.M.; Lettice, L.A.; Essafi, A.; Guadix, J.A.; Slight, J.; Velecela, V.; Hall, E.; Reichmann, J.; Devenney, P.S.; Hohenstein, P.; et al. Wt1 is required for cardiovascular progenitor cell formation through transcriptional control of Snail and E-cadherin. Nat. Genet. 2010, 42, 89-93.

40. Takeichi, M.; Nimura, K.; Mori, M.; Nakagami, H.; Kaneda, Y. The transcription factors Tbx18 and Wt1 control the epicardial epithelial-mesenchymal transition through bi-directional regulation of Slug in murine primary epicardial cells. PLoS One 2013, 8, e57829.

41. Hsu, W.H.; Yu, Y.R.; Hsu, S.H.; Yu, W.C.; Chu, Y.H.; Chen, Y.J.; Chen, C.M.; You, L.R. The Wilms' tumor suppressor Wt1 regulates Coronin $1 \mathrm{~b}$ expression in the epicardium. Exp. Cell Res. 2013, 319, 1365-1381.

42. Wagner, N.; Wagner, K.D.; Scholz, H.; Kirschner, K.M.; Schedl, A. Intermediate filament protein nestin is expressed in developing kidney and heart and might be regulated by the Wilms' tumor suppressor Wt1. Am. J. Physiol. Regul. Integr. Comp. Physiol. 2006, 291, R779-R787.

43. Wagner, N.; Wagner, K.D.; Theres, H.; Englert, C.; Schedl, A.; Scholz, H. Coronary vessel development requires activation of the TrkB neurotrophin receptor by the Wilms' tumor transcription factor Wt1. Genes Dev. 2005, 19, 2631-2642.

44. Niederreither, K.; Vermot, J.; Messaddeq, N.; Schuhbaur, B.; Chambon, P.; Dolle, P. Embryonic retinoic acid synthesis is essential for heart morphogenesis in the mouse. Development 2001, 128, 1019-1031.

45. Chen, T.H.; Chang, T.C.; Kang, J.O.; Choudhary, B.; Makita, T.; Tran, C.M.; Burch, J.B.; Eid, H.; Sucov, H.M. Epicardial induction of fetal cardiomyocyte proliferation via a retinoic acidinducible trophic factor. Dev. Biol. 2002, 250, 198-207.

46. Dyson, E.; Sucov, H.M.; Kubalak, S.W.; Schmid-Schonbein, G.W.; DeLano, F.A.; Evans, R.M.; Ross, J., Jr.; Chien, K.R. Atrial-like phenotype is associated with embryonic ventricular failure in retinoid x receptor alpha -/- mice. Proc. Natl. Acad. Sci. USA 1995, 92, 7386-7390.

47. Jenkins, S.J.; Hutson, D.R.; Kubalak, S.W. Analysis of the proepicardium-epicardium transition during the malformation of the RXRalpha-/- epicardium. Dev. Dyn. 2005, 233, 1091-1101.

48. Zamora, M.; Manner, J.; Ruiz-Lozano, P. Epicardium-derived progenitor cells require betacatenin for coronary artery formation. Proc. Natl. Acad. Sci. USA 2007, 104, 18109-18114.

49. Wu, M.; Smith, C.L.; Hall, J.A.; Lee, I.; Luby-Phelps, K.; Tallquist, M.D. Epicardial spindle orientation controls cell entry into the myocardium. Dev. Cell 2010, 19, 114-125.

50. Duan, J.; Gherghe, C.; Liu, D.; Hamlett, E.; Srikantha, L.; Rodgers, L.; Regan, J.N.; Rojas, M.; Willis, M.; Leask, A.; et al. Wnt1/betacatenin injury response activates the epicardium and cardiac fibroblasts to promote cardiac repair. EMBO J. 2012, 31, 429-442.

51. Rudat, C.; Kispert, A. Wt1 and epicardial fate mapping. Circ. Res. 2012, 111, 165-169.

52. Zhou, B.; Pu, W.T. Genetic Cre-loxP assessment of epicardial cell fate using Wt1-driven Cre alleles. Circ. Res. 2012, 111, e276-e280.

53. Hidai, H.; Bardales, R.; Goodwin, R.; Quertermous, T.; Quertermous, E.E. Cloning of capsulin, a basic helix-loop-helix factor expressed in progenitor cells of the pericardium and the coronary arteries. Mech. Dev. 1998, 73, 33-43.

54. Lu, J.; Richardson, J.A.; Olson, E.N. Capsulin: A novel bHLH transcription factor expressed in epicardial progenitors and mesenchyme of visceral organs. Mech. Dev. 1998, 73, 23-32. 
55. Quaggin, S.E.; Vanden Heuvel, G.B.; Igarashi, P. Pod-1, a mesoderm-specific basic-helix-loophelix protein expressed in mesenchymal and glomerular epithelial cells in the developing kidney. Mech. Dev. 1998, 71, 37-48.

56. Lu, J.; Chang, P.; Richardson, J.A.; Gan, L.; Weiler, H.; Olson, E.N. The basic helix-loop-helix transcription factor capsulin controls spleen organogenesis. Proc. Natl. Acad. Sci. USA 2000, 97 , 9525-9530.

57. Quaggin, S.E.; Schwartz, L.; Cui, S.; Igarashi, P.; Deimling, J.; Post, M.; Rossant, J. The basichelix-loop-helix protein pod1 is critically important for kidney and lung organogenesis. Development 1999, 126, 5771-5783.

58. Azambuja, A.P.; Portillo-Sanchez, V.; Rodrigues, M.V.; Omae, S.V.; Schechtman, D.; Strauss, B.E.; Costanzi-Strauss, E.; Krieger, J.E.; Perez-Pomares, J.M.; Xavier-Neto, J. Retinoic acid and VEGF delay smooth muscle relative to endothelial differentiation to coordinate inner and outer coronary vessel wall morphogenesis. Circ. Res. 2010, 107, 204-216.

59. Acharya, A.; Baek, S.T.; Banfi, S.; Eskiocak, B.; Tallquist, M.D. Efficient inducible Cremediated recombination in Tcf21cell lineages in the heart and kidney. Genesis 2011, 49, 870-877.

60. Funato, N.; Ohyama, K.; Kuroda, T.; Nakamura, M. Basic helix-loop-helix transcription factor epicardin/capsulin/pod-1 suppresses differentiation by negative regulation of transcription. $J$. Biol. Chem. 2003, 278, 7486-7493.

61. Watada, H.; Kajimoto, Y.; Umayahara, Y.; Matsuoka, T.; Morishima, T.; Yamasaki, Y.; Kawamori, R.; Kamada, T. Ubiquitous, but variable, expression of two alternatively spliced mrnas encoding mouse homologues of transcription factors E47 and E12. Gene 1995, 153, 255-259.

62. Barnes, R.M.; Firulli, A.B. A twist of insight - the role of Twist-family bHLH factors in development. Int. J. Dev. Biol. 2009, 53, 909-924.

63. Tandon, P.; Miteva, Y.V.; Kuchenbrod, L.M.; Cristea, I.M.; Conlon, F.L. Tcf21 regulates the specification and maturation of proepicardial cells. Development 2013, 140, 2409-2421.

64. Plotkin, M.; Mudunuri, V. Pod1 induces myofibroblast differentiation in mesenchymal progenitor cells from mouse kidney. J. Cell. Biochem. 2008, 103, 675-690.

65. Murre, C.; McCaw, P.S.; Baltimore, D. A new DNA binding and dimerization motif in immunoglobulin enhancer binding, daughterless, MyoD, and myc proteins. Cell 1989, 56, 777-783.

66. Miyagishi, M.; Hatta, M.; Ohshima, T.; Ishida, J.; Fujii, R.; Nakajima, T.; Fukamizu, A. Cell type-dependent transactivation or repression of mesoderm-restricted basic helix-loop-helix protein, POD-1/capsulin. Mol. Cell. Biochem. 2000, 205, 141-147.

67. Miyagishi, M.; Nakajima, T.; Fukamizu, A. Molecular characterization of mesoderm-restricted basic helix-loop-helix protein, POD-1/capsulin. Int. J. Mol. Med. 2000, 5, $27-31$.

68. Kikuchi, K.; Gupta, V.; Wang, J.; Holdway, J.E.; Wills, A.A.; Fang, Y.; Poss, K.D. Tcf21+ epicardial cells adopt non-myocardial fates during zebrafish heart development and regeneration. Development 2011, 138, 2895-2902. 
69. Lu, X.; Wang, L.; Chen, S.; He, L.; Yang, X.; Shi, Y.; Cheng, J.; Zhang, L.; Gu, C.C.; Huang, J.; et al, Genome-wide association study in Han Chinese identifies four new susceptibility loci for coronary artery disease. Nat. Genet. 2012, 44, 890-894.

70. Schunkert, H.; Konig, I.R.; Kathiresan, S.; Reilly, M.P.; Assimes, T.L.; Holm, H.; Preuss, M.; Stewart, A.F.; Barbalic, M.; Gieger, C.; et al. Large-scale association analysis identifies 13 new susceptibility loci for coronary artery disease. Nat. Genet. 2011, 43, 333-338.

71. Di Meglio, F.; Castaldo, C.; Nurzynska, D.; Romano, V.; Miraglia, R.; Bancone, C.; Langella, G.; Vosa, C.; Montagnani, S. Epithelial-mesenchymal transition of epicardial mesothelium is a source of cardiac CD117-positive stem cells in adult human heart. J. Mol. Cell. Cardiol. 2010, 49, 719-727.

72. Kraus, F.; Haenig, B.; Kispert, A. Cloning and expression analysis of the mouse T-box gene Tbx18. Mech. Dev. 2001, 100, 83-86.

73. Plageman, T.F., Jr.; Yutzey, K.E. T-box genes and heart development: Putting the "t" in heart. Dev. Dyn. 2005, 232, 11-20.

74. Airik, R.; Bussen, M.; Singh, M.K.; Petry, M.; Kispert, A. Tbx18 regulates the development of the ureteral mesenchyme. J. Clin. Invest. 2006, 116, 663-674.

75. Christoffels, V.M.; Mommersteeg, M.T.; Trowe, M.O.; Prall, O.W.; de Gier-de Vries, C.; Soufan, A.T.; Bussen, M.; Schuster-Gossler, K.; Harvey, R.P.; Moorman, A.F.; et al. Formation of the venous pole of the heart from an $\mathrm{Nkx} 2-5$-negative precursor population requires Tbx18. Circ. Res. 2006, 98, 1555-1563.

76. Shelton, E.L.; Yutzey, K.E. Twist1 function in endocardial cushion cell proliferation, migration, and differentiation during heart valve development. Dev. Biol. 2008, 317, 282-295.

77. Christoffels, V.M.; Grieskamp, T.; Norden, J.; Mommersteeg, M.T.; Rudat, C.; Kispert, A. Tbx18 and the fate of epicardial progenitors. Nature 2009, 458, E8-E9; Discussion E9-E10.

78. Grieskamp, T.; Rudat, C.; Ludtke, T.H.; Norden, J.; Kispert, A. Notch signaling regulates smooth muscle differentiation of epicardium-derived cells. Circ. Res. 2011, 108, 813-823.

79. Farin, H.F.; Bussen, M.; Schmidt, M.K.; Singh, M.K.; Schuster-Gossler, K.; Kispert, A. Transcriptional repression by the T-box proteins Tbx18 and Tbx15 depends on Groucho corepressors. J. Biol. Chem. 2007, 282, 25748-25759.

80. Hogan, P.G.; Chen, L.; Nardone, J.; Rao, A. Transcriptional regulation by calcium, calcineurin, and NFAT. Genes Dev. 2003, 17, 2205-2232.

81. de la Pompa, J.L.; Timmerman, L.A.; Takimoto, H.; Yoshida, H.; Elia, A.J.; Samper, E.; Potter, J.; Wakeham, A.; Marengere, L.; Langille, B.L.; et al. Role of the NF-ATc transcription factor in morphogenesis of cardiac valves and septum. Nature 1998, 392, 182-186.

82. Ranger, A.M.; Grusby, M.J.; Hodge, M.R.; Gravallese, E.M.; de la Brousse, F.C.; Hoey, T.; Mickanin, C.; Baldwin, H.S.; Glimcher, L.H. The transcription factor NF-ATc is essential for cardiac valve formation. Nature 1998, 392, 186-190.

83. Combs, M.D.; Yutzey, K.E. VEGF and RANKL regulation of NFATc1 in heart valve development. Circ. Res. 2009, 105, 565-574.

84. Zhou, B.; Wu, B.; Tompkins, K.L.; Boyer, K.L.; Grindley, J.C.; Baldwin, H.S. Characterization of Nfatc1 regulation identifies an enhancer required for gene expression that is specific to provalve endocardial cells in the developing heart. Development 2005, 132, 1137-1146. 
85. Combs, M.D.; Yutzey, K.E. Heart valve development: Regulatory networks in development and disease. Circ. Res. 2009, 105, 408-421.

86. Takayanagi, H.; Kim, S.; Koga, T.; Nishina, H.; Isshiki, M.; Yoshida, H.; Saiura, A.; Isobe, M.; Yokochi, T.; Inoue, J.; et al. Induction and activation of the transcription factor NFATc1 (NFAT2) integrate RANKL signaling in terminal differentiation of osteoclasts. Dev. Cell 2002, 3, 889-901.

87. Rapa, I.; Volante, M.; Cappia, S.; Rosas, R.; Scagliotti, G.V.; Papotti, M. Cathepsin K is selectively expressed in the stroma of lung adenocarcinoma but not in bronchioloalveolar carcinoma. A useful marker of invasive growth. Am. J. Clin. Pathol. 2006, 125, 847-854.

88. Matsumoto, M.; Kogawa, M.; Wada, S.; Takayanagi, H.; Tsujimoto, M.; Katayama, S.; Hisatake, K.; Nogi, Y. Essential role of p38 mitogen-activated protein kinase in cathepsin $\mathrm{K}$ gene expression during osteoclastogenesis through association of NFATc1 and PU.1. J. Biol. Chem. 2004, 279, 45969-45979.

89. Zeini, M.; Hang, C.T.; Lehrer-Graiwer, J.; Dao, T.; Zhou, B.; Chang, C.P. Spatial and temporal regulation of coronary vessel formation by calcineurin-NFAT signaling. Development 2009, 136, $3335-3345$.

90. Casanova, J.C.; Travisano, S.; de la Pompa, J.L. Epithelial-to-mesenchymal transition in epicardium is independent of Snaill. Genesis 2013, 51, 32-40.

91. Carmona, R.; Gonzalez-Iriarte, M.; Macias, D.; Perez-Pomares, J.M.; Garcia-Garrido, L.; Munoz-Chapuli, R. Immunolocalization of the transcription factor Slug in the developing avian heart. Anat. Embryol. 2000, 201, 103-109.

92. Cano, A.; Perez-Moreno, M.A.; Rodrigo, I.; Locascio, A.; Blanco, M.J.; del Barrio, M.G.; Portillo, F.; Nieto, M.A. The transcription factor snail controls epithelial-mesenchymal transitions by repressing E-cadherin expression. Nat. Cell Biol. 2000, 2, 76-83.

93. Tao, G.; Levay, A.K.; Gridley, T.; Lincoln, J. Mmp15 is a direct target of Snail during endothelial to mesenchymal transformation and endocardial cushion development. Dev. Biol. 2011, 359, 209-221.

94. Tao, G.; Miller, L.J.; Lincoln, J. Snail is important for avian epicardial cell transformation and motility. Dev. Dyn. 2013, 242, 699-708.

95. Merki, E.; Zamora, M.; Raya, A.; Kawakami, Y.; Wang, J.; Zhang, X.; Burch, J.; Kubalak, S.W.; Kaliman, P.; Belmonte, J.C.; et al. Epicardial retinoid X receptor alpha is required for myocardial growth and coronary artery formation. Proc. Natl. Acad. Sci. USA 2005, 102, 18455-18460.

96. Mahtab, E.A.; Wijffels, M.C.; van den Akker, N.M.; Hahurij, N.D.; Lie-Venema, H.; Wisse, L.J.; Deruiter, M.C.; Uhrin, P.; Zaujec, J.; Binder, B.R.; et al. Cardiac malformations and myocardial abnormalities in Podoplanin knockout mouse embryos: Correlation with abnormal epicardial development. Dev. Dyn. 2008, 237, 847-857.

97. Batlle, E.; Sancho, E.; Franci, C.; Dominguez, D.; Monfar, M.; Baulida, J.; Garcia de Herreros, A. The transcription factor snail is a repressor of E-cadherin gene expression in epithelial tumour cells. Nat. Cell Biol. 2000, 2, 84-89.

98. del Monte, G.; Casanova, J.C.; Guadix, J.A.; MacGrogan, D.; Burch, J.B.; Perez-Pomares, J.M.; de la Pompa, J.L. Differential Notch signaling in the epicardium is required for cardiac inflow development and coronary vessel morphogenesis. Circ. Res. 2011, 108, 824-836. 
99. Timmerman, L.A.; Grego-Bessa, J.; Raya, A.; Bertran, E.; Perez-Pomares, J.M.; Diez, J.; Aranda, S.; Palomo, S.; McCormick, F.; Izpisua-Belmonte, J.C.; et al. Notch promotes epithelialmesenchymal transition during cardiac development and oncogenic transformation. Genes Dev. 2004, 18, 99-115.

100. Lee, M.P.; Yutzey, K.E. Twist1 directly regulates genes that promote cell proliferation and migration in developing heart valves. PLoS One 2011, 6, e29758.

101. Barnes, R.M.; Firulli, B.A.; VanDusen, N.J.; Morikawa, Y.; Conway, S.J.; Cserjesi, P.; Vincentz, J.W.; Firulli, A.B. Hand2 loss-of-function in Hand1-expressing cells reveals distinct roles in epicardial and coronary vessel development. Circ. Res. 2011, 108, 940-949.

102. Smith, C.L.; Baek, S.T.; Sung, C.Y.; Tallquist, M.D. Epicardial-derived cell epithelial-tomesenchymal transition and fate specification require PDGF receptor signaling. Circ. Res. 2011, $108, \mathrm{e} 15-\mathrm{e} 26$.

103. Cserjesi, P.; Brown, D.; Ligon, K.L.; Lyons, G.E.; Copeland, N.G.; Gilbert, D.J.; Jenkins, N.A.; Olson, E.N. Scleraxis: A basic helix-loop-helix protein that prefigures skeletal formation during mouse embryogenesis. Development 1995, 121, 1099-1110.

104. Lincoln, J.; Alfieri, C.M.; Yutzey, K.E. BMP and FGF regulatory pathways control cell lineage diversification of heart valve precursor cells. Dev. Biol. 2006, 292, 292-302.

105. Schweitzer, R.; Chyung, J.H.; Murtaugh, L.C.; Brent, A.E.; Rosen, V.; Olson, E.N.; Lassar, A.; Tabin, C.J. Analysis of the tendon cell fate using Scleraxis, a specific marker for tendons and ligaments. Development 2001, 128, 3855-3866.

106. Levay, A.K.; Peacock, J.D.; Lu, Y.; Koch, M.; Hinton, R.B., Jr.; Kadler, K.E.; Lincoln, J. Scleraxis is required for cell lineage differentiation and extracellular matrix remodeling during murine heart valve formation in vivo. Circ. Res. 2008, 103, 948-956.

107. Espira, L.; Lamoureux, L.; Jones, S.C.; Gerard, R.D.; Dixon, I.M.; Czubryt, M.P. The basic helix-loop-helix transcription factor Scleraxis regulates fibroblast collagen synthesis. J. Mol. Cell. Cardiol. 2009, 47, 188-195.

108. Akiyama, H.; Chaboissier, M.C.; Behringer, R.R.; Rowitch, D.H.; Schedl, A.; Epstein, J.A.; de Crombrugghe, B. Essential role of Sox 9 in the pathway that controls formation of cardiac valves and septa. Proc. Natl. Acad. Sci. USA 2004, 101, 6502-6507.

109. Kikuchi, K.; Poss, K.D. Cardiac regenerative capacity and mechanisms. Ann. Rev. Cell Dev. Biol. 2012, 28, 719-741.

110. Poss, K.D.; Wilson, L.G.; Keating, M.T. Heart regeneration in zebrafish. Science 2002, 298, 2188-2190.

111. Kikuchi, K.; Holdway, J.E.; Major, R.J.; Blum, N.; Dahn, R.D.; Begemann, G.; Poss, K.D. Retinoic acid production by endocardium and epicardium is an injury response essential for zebrafish heart regeneration. Dev. Cell 2011, 20, 397-404.

112. Lepilina, A.; Coon, A.N.; Kikuchi, K.; Holdway, J.E.; Roberts, R.W.; Burns, C.G.; Poss, K.D. A dynamic epicardial injury response supports progenitor cell activity during zebrafish heart regeneration. Cell 2006, 127, 607-619.

113. Jopling, C.; Sleep, E.; Raya, M.; Marti, M.; Raya, A.; Izpisua Belmonte, J.C. Zebrafish heart regeneration occurs by cardiomyocyte dedifferentiation and proliferation. Nature 2010, 464, 606-609. 
114. Kikuchi, K.; Holdway, J.E.; Werdich, A.A.; Anderson, R.M.; Fang, Y.; Egnaczyk, G.F.; Evans, T.; Macrae, C.A.; Stainier, D.Y.; Poss, K.D. Primary contribution to zebrafish heart regeneration by gata4(+) cardiomyocytes. Nature 2010, 464, 601-605.

115. Porrello, E.R.; Mahmoud, A.I.; Simpson, E.; Hill, J.A.; Richardson, J.A.; Olson, E.N.; Sadek, H.A. Transient regenerative potential of the neonatal mouse heart. Science 2011, 331, 1078-1080.

116. Bock-Marquette, I.; Shrivastava, S.; Pipes, G.C.; Thatcher, J.E.; Blystone, A.; Shelton, J.M.; Galindo, C.L.; Melegh, B.; Srivastava, D.; Olson, E.N.; et al. Thymosin beta4 mediated PKC activation is essential to initiate the embryonic coronary developmental program and epicardial progenitor cell activation in adult mice in vivo. J. Mol. Cell. Cardiol. 2009, 46, 728-738.

117. Russell, J.L.; Goetsch, S.C.; Gaiano, N.R.; Hill, J.A.; Olson, E.N.; Schneider, J.W. A dynamic Notch injury response activates epicardium and contributes to fibrosis repair. Circ. Res. 2011, $108,51-59$.

(C) 2013 by the authors; licensee MDPI, Basel, Switzerland. This article is an open access article distributed under the terms and conditions of the Creative Commons Attribution license (http://creativecommons.org/licenses/by/3.0/). 